\title{
Elevated mortality of fish larvae on coral reefs drives the evolution of larval movement patterns
}

\author{
C. Dytham ${ }^{1}$, S. D. Simpson ${ }^{2, *}$ \\ ${ }^{1}$ Department of Biology, University of York, PO Box 373, York YO10 5YW, UK \\ ${ }^{2}$ Institute of Evolutionary Biology, School of Biological Sciences, University of Edinburgh, Kings Buildings, \\ Edinburgh EH9 3JT, UK
}

\begin{abstract}
Coral reef fishes typically undergo a pelagic larval phase prior to recruitment to reef habitat. This is potentially risky, but likely to be important in connecting populations and avoiding local crowding. Predation pressures on larvae on and off the reef are likely to differ both in origin and intensity. In this study, we used individual-based models to explore in isolation the effect of elevated levels of larval mortality on the reef in 22 different landscapes. We allowed the movement of highly simplified larvae to evolve through selection and mutation events and tracked emerging strategies over 180 generations. The pressure of increased larval mortality on the reef affected overall population sizes and selected for higher levels of larval movement. However, the evolution of movement was constrained, and self-recruitment back to the reef of origin was prevalent, with levels rarely dropping below $50 \%$. The evolved strategies were highly landscape specific, suggesting that movement in contiguous reefs is more readily evolved than at isolated reefs. Future development of this simulation approach will provide a valuable research tool for exploring important evolutionary, ecological, and management-based questions.
\end{abstract}

KEY WORDS: Evolved strategy $\cdot$ Larvae $\cdot$ Coral reef fishes $\cdot$ Active dispersal $\cdot$ Self-recruitment

\section{INTRODUCTION}

The majority of fishes that inhabit coral reef environments in their adult phases have pelagic phases earlier in their life histories (Leis 1991). This is counterintuitive, as movement away from adult breeding sites could prevent subsequent settlement to suitable habitat. However, coupled with this obvious risk, there are several potential benefits to this strategy: evading predation (Johannes 1978), reduced parent-offspring competition (Godfray 1995), exploitation of new habitats (Doherty et al. 1985) and reduced inbreeding depression (Motro 1991). However, selection can only act on the individual, so evolved strategies must be reinforced in the short term in order to succeed in the long term (see Bonhomme \& Planes 2000 for a review).

The pelagic phase is an evolutionarily stable strategy, and the study of this 'black box' in the life history of reef fishes has been the focus of much work in recent years (review in Leis \& McCormick 2002), leading to a fundamental debate about the nature of coral reef fish populations. At one extreme, because large numbers of offspring have a potentially highly dispersive period, populations could be considered 'open', with many larvae moving between subpopulations (review in Sale 1991). This predicts the extensive biogeographical ranges exhibited by some species and, through recruitment limitation and the lottery hypothesis, may explain the fish assemblages found on different reefs. It also explains why some fishes are occasionally found far away from reefs during their larval phase. At the other extreme, fish may be dispersed very little and, through various passive and active processes, may recruit back to the reefs on which they were spawned (i.e. self-recruitment; Almany et al. 2007). Of course, the behaviour of real populations probably lies within these extremes, in complex metapopulation structures (James et al. 2002). A better 
understanding of the metapopulation structures of coral reef fishes will greatly improve the strategies employed by fisheries and conservation managers to protect populations or exploit them sustainably (Warner et al. 2000).

The study of reef fish larvae in their natural environment is difficult. These fishes are small, may be highly diffuse, and often exist outside safe conditions for SCUBA (but see Leis et al. 1996). Therefore, studies have been restricted to 4 approaches. First, some empirical studies have used late-stage larvae from families that can be collected with light traps. From these studies we have learned that many larvae are strong swimmers (Leis 2006), that they are able to determine the direction of reefs (Leis et al. 1996), and are attracted to and can orient towards sound (Simpson et al. 2004, Simpson et al. 2005a, Montgomery et al. 2006). Second, other empirical studies on the early stages of some species that can be reared in captivity have provided information on the ontogenic development of hearing (Simpson et al. 2005b, Montgomery et al. 2006) and swimming abilities (Leis 2006). Third, techniques have been applied that glean information about the larval period indirectly. These studies include tagging eggs to study self-recruitment (Almany et al. 2007), comparing trace elements in the otoliths (calcareous structures in the inner ear) of recruits with the chemical composition of surrounding water masses to infer movements (Swearer et al. 1999), and using genetic markers to identify patterns of, or barriers to, gene flow (Planes \& Fauvelot 2002). Finally, theoretical modelling approaches have been used to look at both the effects of oceanographic regimes on dispersal and retention on many spatial scales (Cowen et al. 2006) and the properties of larval behaviour that may drive active movement towards reefs (Armsworth 2000, Codling et al. 2004). To date, these models have mainly focussed on individuals, probabilities, and single larval recruitment events over ecological timescales.

In this study we ignored the stochasticity of local oceanography and instead followed the evolution of dispersal strategies through multiple generations. We used individual-based models (IBMs) to simulate the behaviour of reef fish populations. Similar models have been used to study dispersal in many other contexts (Travis \& Dytham 1998, Travis et al. 1999). Our models are necessarily simplistic and take place in imaginary arenas, allowing us to explore the effects of specific parameters on the dispersal strategies that evolve to adapt to different conditions. We allowed dispersal strategies to evolve, explored the effects of elevated on-reef larval mortality rates, and identified landscape characteristics that select for different strategies. We investigated the behaviour of populations by measur- ing population sizes and extinction rates and by tracking connectivity between reefs and levels of selfrecruitment.

\section{METHODS}

Landscape design. The 22 landscapes we used in this study were generated randomly on a square grid of 62500 cells (we envisaged a cell as being about $100 \times 100 \mathrm{~m}$ ) using the following procedure. First, 6 islands were generated to take up about $2.6 \%$ of the arena using the following algorithm: (1) three island 'seed' cells were randomly located; (2) half of the island cells were built randomly on neighbouring cells around the initial seeds (a neighbouring cell is one of the 8 surrounding cells); (3) more island seeds were added, and the other half of the island cells were built around the 6 islands; (4) any non-island cells enclosed at the 4 cardinal points by island cells were filled in. Second, following island generation, 5 reef 'seeds' were dropped on cells adjacent to islands, and 1250 reef cells were then built around these seeds $(2 \%$ of the arena). To maintain discrete reefs, the reefs were prevented from touching. This process produced landscapes with 3 larger and 3 smaller islands with variable sizes, locations, and shapes and 5 discrete reefs lying just off the islands (examples in Fig. 1).
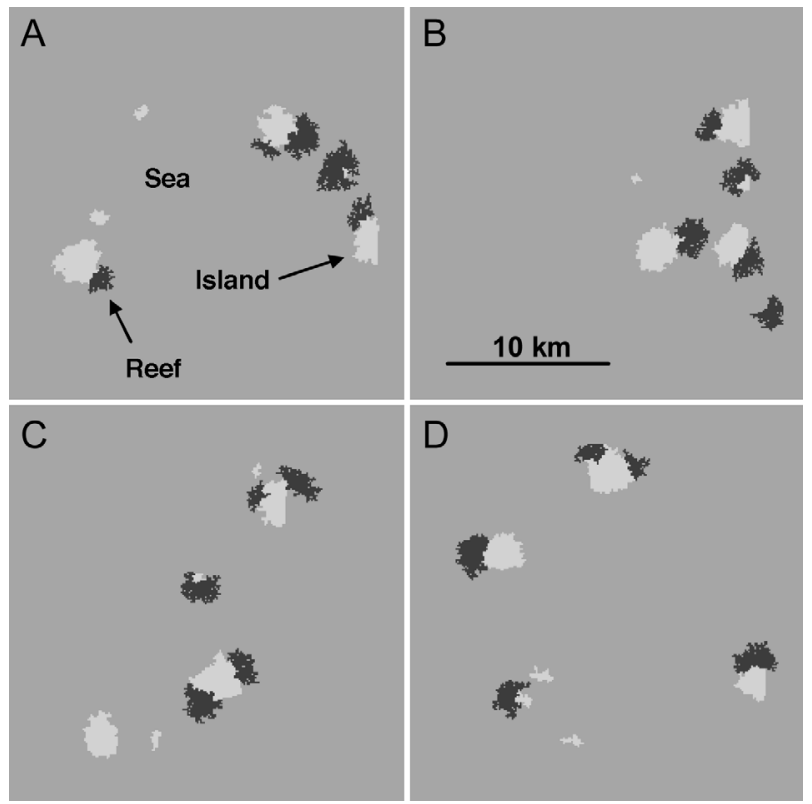

Fig. 1. Four example landscapes. Each comprises $250 \times 250$ cells and consists of 6 islands ( $2.6 \%$ of the arena) and 5 reefs ( $2 \%$ of the arena). One cell is $100 \times 100 \mathrm{~m}$; each arena covers $625 \mathrm{~km}^{2}$. Scale in (B) applies to all 4 landscapes 
Fish life histories and larval mortality. In order to isolate the effects of individual parameters, we used a simplified fish life history, with no post-settlement (on-reef) processes except density-dependent fecundity. The order of events in each generation was as follows: birth, larval phase, settlement (or death), spawn once (with density effect), death. For simplicity, there was no overlap of generations (i.e. annual), larvae could not settle to a reef during the larval phase prior to a 'settlement window', there was no post-settlement mortality, and there was no sexual interaction (i.e. modelling only females). If a single fish occupied a reef cell it would have a number of offspring drawn from a discrete, uniform distribution with a mean of 10 and limits of zero and 20. Each reef cell had an equilibrium density of 10 , and if more than one fish occupied it ( $\mathrm{n}>1$ ), they would each produce offspring drawn from a distribution with a mean of $10 / \mathrm{n}$, with limits of zero to $20 / \mathrm{n}$.

At each time step (10 $\mathrm{min}$ ) in the model throughout the larval period, the larvae were subjected to a chance of mortality if they were on the reef $\left(M_{\mathrm{r}}\right.$, where $M=$ probability of mortality in a 10 min time step [not instantaneous mortality, normally denoted as $Z$ ]). We did not include mortality at sea $\left(M_{\text {sea }}\right)$-although in reality pelagic starvation (Margulies 1993) and predation (Bailey \& Houde 1989) are important factorssince we were interested in relative larval mortality rates between reef and pelagic habitats $\left(M_{\mathrm{r}}=M_{\text {reef }}-\right.$ $M_{\text {sea }}$ ). Testing the model where $M_{\text {sea }}>M_{\text {reef }}$ (unlikely due to the great density of potential predators on the reef compared to at sea), or with equal larval mortality at sea and on the reef $\left(M_{\text {reef }}=M_{\text {sea }}\right)$ predicts a strategy of negligible dispersal, and varying the magnitude of equivalent $M_{\text {reef }}$ and $M_{\text {sea }}$ larval mortality parameters without changing $M_{\mathrm{r}}$ leads to the evolution of similar strategies but with different sustainable population sizes. Here, we investigated the effects of elevated onreef larval mortality rates $\left(M_{\mathrm{r}}>0\right)$ in the parameter space from where populations persisted in all landscapes to where most populations went extinct: 0.0004 $\leq M_{\mathrm{r}} \leq 0.0009$ (in 0.00005 increments). Since larvae could not settle before 3000 time steps (see below), this represents a range in survival by staying on the reef of between $30 \%$ at $M_{\mathrm{r}}=0.0004$, and $<7 \%$ at $M_{\mathrm{r}}=0.0009$. These are extremely high survival rates for fish larvae, but they are balanced by our parameter for fecundity where the mean number of offspring is 10 . We kept fecundity and mortality low to reduce computational load and permit many realisations of the model. Examination of (time-consuming) simulations with high levels of fecundity balanced by (in addition to $M_{\mathrm{r}}$ ) a background mortality to maintain similar population sizes showed that the emerging strategies were qualitatively similar.
Larval movements, inheritance and evolution. Our larval fish was modelled using current parameters from empirical studies on Pomacentridae (damselfish) larvae (Leis et al. 1996, Leis \& McCormick 2002, Leis 2006). Each fish had a fixed dispersal strategy $(q)$ throughout its life, which ranged from zero (never move) to 1 (move on every time step of $10 \mathrm{~min}$ ). Individuals differed only in dispersal strategy: there was no trade-off between dispersal and either competitive ability or fecundity. At each time step, a larva could move at random to any of the surrounding 8 cells unless it was dry land, effectively giving a movement speed of either 17 (straight) or 24 (diagonal) $\mathrm{cm} \mathrm{s}^{-1}$. Individuals could not distinguish between reef and ocean patches during dispersal and new moves were independent of previous moves (i.e. individuals could backtrack). Unlike the model of Travis et al. (1999), we did not consider density-dependent dispersal, which is highly unlikely to apply to pelagic dispersal of reef fish larvae in 1.0 ha cells. If a fish attempted to move out of the arena, it was held where it was, and the model moved on 1 time step. This is the same as assuming equal import into, and export from our arena (where imported larvae have equivalent strategies to exported fish). The minimum length of the larval life was set at 3000 time steps, whereafter if a larva moved to a reef cell it would settle. The maximum length of larval life was set at 4000 time steps, effectively giving a pelagic larval duration of $\sim 21 \mathrm{~d}$, followed by a settlement window of $\sim 7 \mathrm{~d}$, followed by death if still at sea. If a larva had the strategy $q=0.2$, it would move approximately 600 times before the settlement window opened, ultimately moving randomly about $74 \mathrm{~km}$, or 3 times the length of the arena (but with a mean displacement of zero), before being competent to settle. It should be noted that since we did not have larval mortality at sea per se, there was no cost to moving while the settlement window was open. In reality this is unlikely to be true, and exploration of the true costs and benefits of flexibility in time of settlement and the ability to delay metamorphosis warrants separate study in its own right.

Individuals inherited the dispersal strategy of their parent but with a $1 \%$ probability of mutation. Mutations were of 2 types. In $90 \%$ of mutations, the inherited strategy had a $q$-value drawn from a continuous, uniform distribution ranging from 80 to $120 \%$ of the parental strategy (hence, a small mutation). In $10 \%$ of mutations, the mutant strategy was drawn from a uniform distribution between zero and 1 (hence, potentially, a radical mutation). In this way, populations were able to evolve in response to different conditions.

Starting conditions, realisations and objectives. For each realisation of the model, we started with 1000 individuals located randomly on reef cells, with an 
equal chance of being in each cell. The initial dispersal strategies were drawn from a uniform distribution between zero and 1 . Each realisation of the model ran for 180 generations.

We report the results of 10 realisations in each of 22 landscapes for 11 fixed relative mortality rates (2420 realisations). We tracked the global population size, the global mean $q$, and its standard deviation. We also recorded the number of individuals that self-recruited to their natal reef and the number of individuals that dispersed to a reef other than their natal reef.

We used the model to explore (1) the effect of elevated larval mortality on the reef on (a) the resilience of populations, (b) the global dispersal strategy and the global level of self-recruitment, and (c) the

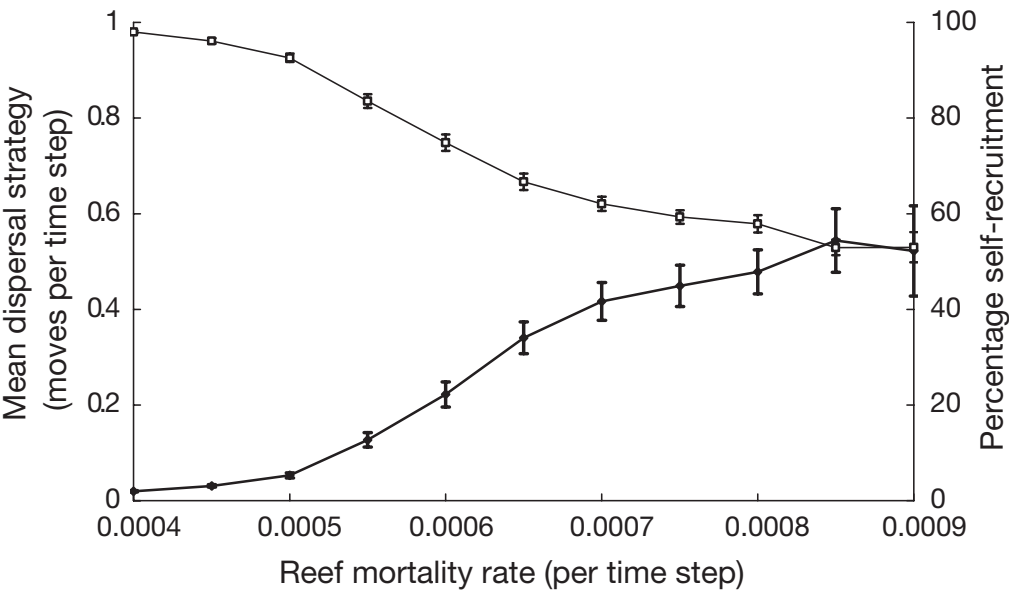

Fig. 3. Effect of on-reef larval mortality rate on the dispersal strategy (upward slope) and on the level of self-recruitment of larvae back to their natal reefs (downward slope). Each data point represents the mean from 220 populations (22 landscapes $\times 10$ replicates). Means $\pm 95 \% \mathrm{Cl}$ global population size, and the interactive effect of these on fecundity; and (2) the interaction of the effect of the landscape and elevated larval mortality on the reef on (d) the resilience of populations, (e) the evolved dispersal strategies, and (f) the levels of self-recruitment.

\section{RESULTS}

There was a strong effect of larval mortality rates on the reef on the resilience of populations over the 180 generations tracked in each realisation (Fig. 2). At low levels of mortality ( 0.0004 to 0.00055 per time step; 30 and $19 \%$ on-reef survival during the larval phase, respectively), there were no extinctions in any of the 22

landscapes in any of 10 realisations. At higher relative mortality rates, there was increased extinction of populations, with a mean of only 0.2 surviving at $M_{\mathrm{r}}=$ 0.0009 . These extinctions were not randomly distributed among the landscapes, and some landscapes still had populations in up to 8 of 10 realisations, while 13 of 22 landscapes had no populations after any of the 10 realisations at this high mortality.

There was a marked effect on the dispersal strategy that evolved as the larval mortality rate on the reef $\left(M_{\mathrm{r}}\right)$ increased (Fig. 3). At lower mortality rates (0.0004 per time step, $\sim 30 \%$ survival on the reef), where the population survived for 180 generations in all 220 realisations (Fig. 2), the evolved dispersal strategy was one of almost no movement $(q=0.02)$. At this low larval mortality level, different landscapes had no effect, so the variance remained low. An increase in larval mortality on the reef to 0.00055 (19\% survival on the reef), which was still survived by all 220 populations, resulted in a strategy where larvae moved more than $10 \%$ of the time. The global dispersal strategy appears to reach an asymptote (of $q \approx 0.5$ ) at the higher levels of mortality, but the number of populations that survived was greatly reduced $(41 / 220$ at 0.0009$)$. An increase in the variance of the strategies occurred at higher mortalities, with some populations having high ( $q \sim 1)$, and others retaining low $(q<0.2)$ movement strategies.

Larval mortality rates on the reef affected the number of larvae that recruited 


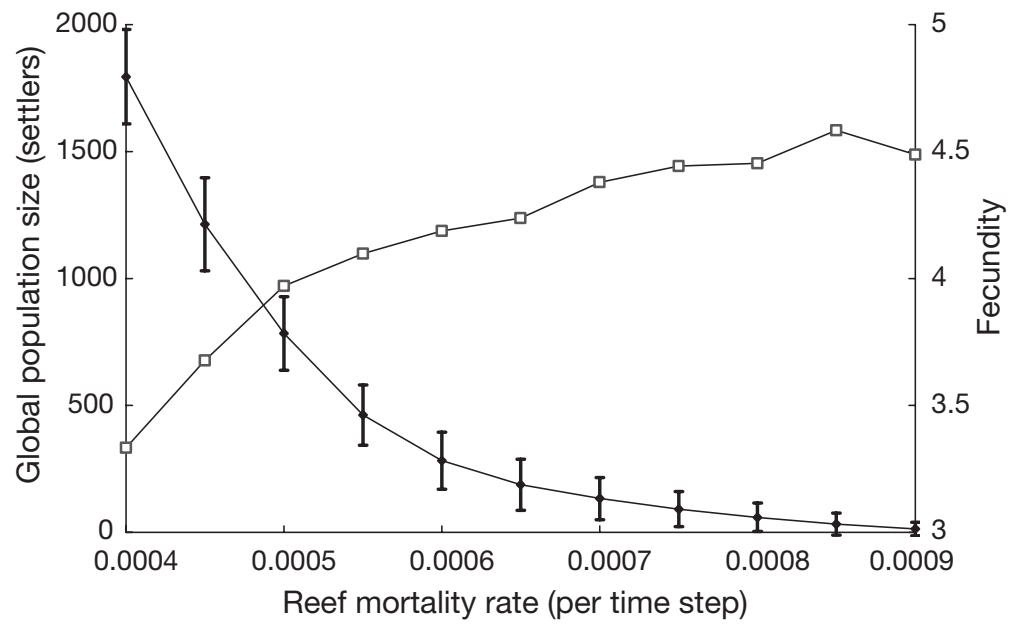

Fig. 4. Effect of on-reef larval mortality rate on the adult population size (downward slope) and realised fecundity (upward slope). Each data point represents the mean from 220 populations (22 landscapes $\times 10$ replicates). Means $\pm 95 \% \mathrm{CI}$

back to their natal reefs (Fig. 3). At low mortality rates, almost all of the surviving larvae recruited to their natal reefs. At $M_{\mathrm{r}}=0.00065$, where the mean dispersal strategy was greater than 0.3 , dispersal to other reefs increased to about $35 \%$. However, as mortality increased further, the level of self-recruitment reached an asymptote of around $50 \%$. In 2420 realisations of the model, the lowest self-recruitment rate was $31.3 \%$ (landscape in Fig. $1 C_{\text {; }}$ at $M_{\mathrm{r}}=0.0009$ per time step).

Global population size decreased as larval mortality on the reef increased (Fig. 4). At low levels of mortality on the reef, a total adult population of around 1800 individuals was realised, and the population was also greater than the initial population (1000) at $M_{\mathrm{r}}=0.00045$ per time step. However, a decrease in survival on the reef from $30 \%\left(M_{\mathrm{r}}=0.0004\right)$ to $17 \%\left(M_{\mathrm{r}}=0.0006\right)$ resulted in a 6-fold decrease in the population size, and caused 7 populations to become extinct (Fig. 2). At $M_{\mathrm{r}}=0.0008$ ( $9 \%$ survivorship on the reef), where more than half of the populations still persisted for the 180 generations, the global population was reduced to around 60 adults. The effect of density-dependent fecundity on the potential numbers of offspring (10 per adult) was marked at low mortality rates (0.0004 per time step), with only 6000 larvae actually produced from 1800 adults (3.3 per adult). However, at high relative larval mortality rates (0.0008 to 0.0009 per time step), fecundity was higher, at around 4.5 larvae per adult.
There was substantial variation in the critical on-reef larval mortality rates that caused populations to go extinct within 180 generations in different landscapes (Fig. 5). Some landscapes could support populations with high levels of larval mortality on the reef (e.g. 8/10 populations survived at $M_{\mathrm{r}}=0.0009$, or $7 \%$ survival on the reef in landscape of Fig. 1B). However, at $M_{\mathrm{r}}=0.0009$, extinction occurred in all 10 replicates in 13/22 landscapes. Extinction occurred at the lowest on-reef larval mortality rates for landscape D (Fig. 1D), with all 10 of the populations going extinct when $M_{\mathrm{r}}=0.0007(12 \%$ survival on the reef).

Marked differences also occurred in the dispersal strategies that evolved in different landscapes with increased larval mortality rates (Fig. 6). Despite a decrease in the survival rate on the reef from $30 \%$ $\left(M_{\mathrm{r}}=0.0004\right)$ to $14 \%\left(M_{\mathrm{r}}=0.00065\right)$, there was no change in the dispersal strategy in landscape D. This population went extinct at higher levels of mortality. Landscapes A and B (Fig. 1A, B) showed a gradual increase in the dispersal strategy with increased onreef larval mortality, although at $M_{\mathrm{r}}=0.0009$, larvae still moved only 18 and $37 \%$ of the time, respectively. Populations in Landscape C (Fig. 1C) developed a more active dispersal strategy even at low mortality levels, with larvae moving $\sim 50 \%$ of the time when onreef larval survivorship was still $19 \%\left(M_{\mathrm{r}}=0.00055\right)$, and $\sim 80 \%$ of the time when survivorship was reduced to $7 \%\left(M_{\mathrm{r}}=0.0009\right)$.

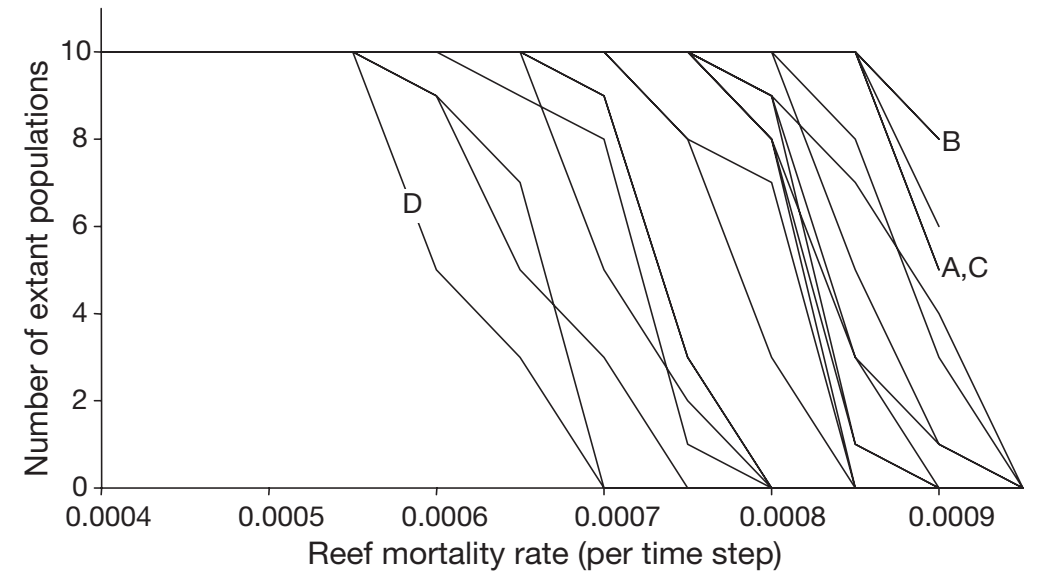

Fig. 5. Number of extant populations after 180 generations from 10 replicates for each of 22 different landscapes. Lines labelled A to D refer to the landscapes in Fig. 1. In D, extinction occurred in 5/10 simulations at $M_{\mathrm{r}}=$ 0.0006 , and all populations went extinct when $M_{\mathrm{r}}=0.0007$, whereas in B, only $2 / 10$ simulations led to extinction when $M_{\mathrm{r}}=0.0009$ 


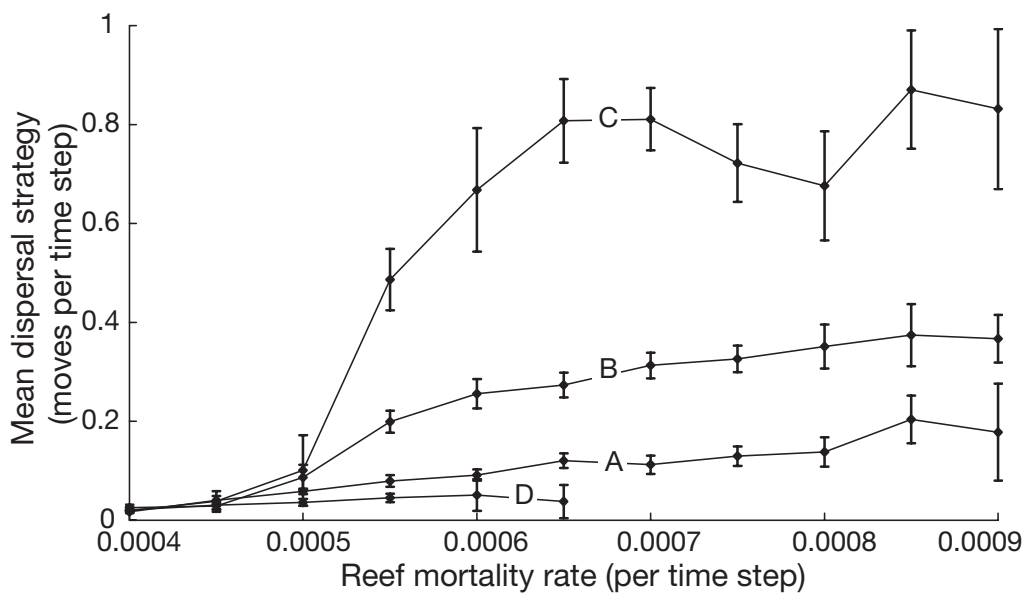

Fig. 6. Effect of on-reef larval mortality rate on the mean dispersal strategy for populations from 4 different landscapes (Fig. 1A-D). Means $\pm 95 \% \mathrm{CI}$, $\mathrm{n}=10$

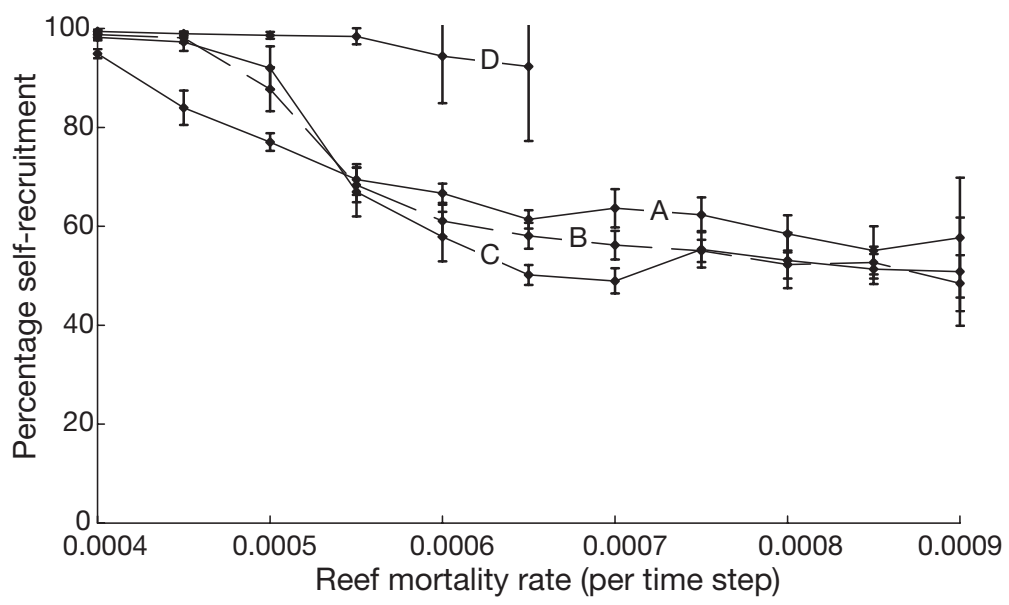

Fig. 7. Effect of on-reef larval mortality rate on the level of self-recruitment of larvae back to their natal reefs for 4 different landscapes (Fig. 1A-D). Means $\pm 95 \% \mathrm{CI}, \mathrm{n}=10$

Landscapes affected the population sizes that could be sustained at different relative larval mortality rates. At low mortality rates, populations A to D (Fig. 1) all increased over 180 generations from the initial 1000 adults in Generation 1. Landscape A sustained the largest populations and had an average of $84 \%$ greater population size than Landscape $C$, which had the lowest sustained populations at higher mortalities. Populations did not survive in Landscape D when larval mortality on the reef exceeded $M_{\mathrm{r}}=0.00065$ (14\% survivorship on the reef).

Although there was a general decrease in the levels of self-recruitment as on-reef larval mortality increased, there was considerable variation in the response in different landscapes (Fig. 7). Self-recruitment did not drop below $90 \%$ in Landscape D, and populations did not persist when the mortality rate of larvae on the reef exceeded 0.00065 per time step. Dispersal between reefs evolved at the lower levels of mortality in Landscape $\mathrm{A}$, with a $4 \%$ decrease in survivorship on the reef $\left(M_{\mathrm{r}}=0.0004\right.$ to $M_{\mathrm{r}}=0.00045$ ) driving a $15 \%$ decrease in self-recruitment. At high levels of mortality, the 3 landscapes that supported populations (A, B, C) all produced asymptotes of around $60 \%$ self-recruitment (Fig. 7).

\section{DISCUSSION}

\section{Interpretation of results}

Our results show that an elevated rate of larval mortality on the reef relative to that at sea has a marked effect on the success of populations. At low levels of larval mortality, all populations survived over 180 generations (Fig. 2). However, at high levels of mortality, many of the populations became extinct. This pattern of extinction was not uniform, and populations persisted in some landscapes at high levels of mortality (Fig. 5). Meanwhile, at mid-range levels of larval mortality (equivalent to $\sim 12 \%$ survival on the reef), populations in other landscapes crashed. It has been proposed that the larvae of coral reef fishes develop at sea as a means of postponing their encounter with the 'wall of mouths' on the reef until fully competent to settle (Hamner et al. 1988). Although difficult to measure empirically, on-reef larval mortality rate estimates over the first few days immediately following settlement range from 56\% (Almany \& Webster 2006) to almost $100 \%$ (Dufour et al. 1996), while an estimate for the larval mortality of damselfish Acanthochromis polyacanthus, which lacks a pelagic larval phase, is $46 \%$ (Booth \& Alquezar 2002), despite elevated levels of parental care. An empirical estimate for mortality at sea is 0.1 to $0.5 \mathrm{~d}^{-1}$ (Houde 1989), which translates to a survival at sea over $21 \mathrm{~d}$ (as modelled in this study) of $10.9 \%$ to $0.00005 \%$, or $M_{\text {sea }}$ values of 0.0007 to 0.005 . Mortality at sea is not included in our model, since we investigated relative mortality rates and balanced low mortality with low fecundity (mean of 10 offspring) to reduce realisation times. Our $M_{\mathrm{r}}$ values of 0.0004 to 0.0009 represent daily on-reef mortality rates of larvae that exceed pelagic mortality by 0.06 to $0.12 \mathrm{~d}^{-1}$. Broadcast spawning fishes release thousands of small, 
buoyant eggs into the water column, the vast majority of which perish, and even the larvae of demersal spawning fishes such as our model damselfish, which emerge well developed from a spawn of a few hundred large eggs, suffer high levels of mortality. Our results indicate that whatever the real values of relative mortality rates may be, the strategic response that is selected for is landscape-specific, and will probably possess a critical threshold between a strategy of little movement and one of dispersal.

An increase in the larval mortality rate on the reef relative to that at sea forced model populations to evolve a strategy of higher movement rates. At low levels of mortality, despite survivorship of only $\sim 30 \%$ of offspring on the reef, larvae moved very little, presumably to ensure settlement at the end of the larval period (Fig. 3). Even at high mortality rates, the dispersal strategy was to move around only $50 \%$ of the time. This does not necessarily imply that larvae were dispersing between reefs, and most likely emerged as a strategy to ensure that larvae moved away from the reef at the start of the pelagic larval duration. This upper limit may indicate a balance of ensuring initial movement away from the reef, while preventing excessive displacement from the reef prior to the start of the settlement window. These findings are supported by empirical studies that report strategies for maximising initial movement of larvae away from reef habitats. Species that spawn their (buoyant) eggs into the water column may do so in down-current locations (Hensley et al. 1994) or during favourable tidal conditions (Johannes 1978) to maximise their export away from egg predators. Similarly, the emergence of larvae from eggs spawned demersally on the reef usually occurs after dusk, presumably to elude visual predators (McAlary \& McFarland 1993). Once larvae are at sea, however, there is evidence that oceanographic features such as eddies may contribute to the retention of larvae (see review in Swearer et al. 2002).

The landscape was an important determinant in the dispersal strategy that evolved at a given relative mortality rate. Populations in Landscape A (Fig. 1A) evolved only low dispersal strategies even at high larval mortality rates (Fig. 6). Although Landscape A had reefs that were a mean of $9.1 \mathrm{~km}$ apart (mean of 10 pairwise distances between 5 reef centroids), the standard deviation of distances was the largest at $14.2 \mathrm{~km}$. This is due to 1 reef on the left-hand-side being relatively isolated (and likely uninhabited at higher mortalities), but with the remaining 4 reefs lying in close proximity. We interpret this as a response to a contiguous reef arrangement (cf. Great Barrier Reef), where low levels of movement ensure larvae move out to sea and away from the high predation on the reef, but then either self-recruit or settle to neighbouring reefs with little movement needed. Far higher dispersal rates evolved at increased relative mortality rates in Landscape C (Fig. 1C). Landscape $C$ also had reefs which were a mean of $9.1 \mathrm{~km}$ apart, but with a standard deviation of $9.9 \mathrm{~km}$, suggesting that the reefs are more evenly distributed. We interpret this as being a similar result to that for the 4 closely situated reefs in Landscape A, but due to the reefs being spread further apart, higher rates of movement were selected for to enable dispersal between reefs. Our results and interpretation for Landscape B (Fig. 1B) sit as intermediate between Landscapes A and C (mean distance $6.9 \mathrm{~km}$, $\mathrm{SD}=6.9 \mathrm{~km}$ ). Landscape D (Fig. 1D), however, did not sustain populations at high larval mortality levels, and there was no departure from a strategy of no movement, despite increased mortality levels. With a mean distance between reefs of $13.7 \mathrm{~km}(\mathrm{SD}=11.4 \mathrm{~km})$, our interpretation is that the reefs were spread too far apart for populations to sustain a dispersal strategy between reefs, and ultimately succumbed to mortality pressures. This would be the case for populations on isolated sea mounts, and represents a lack of the 'rescue effect', where populations are saved from extinction by immigration from other sources (Brown \& Kodric-Brown 1977). From our results, it is clear that landscapes influence the strategies that evolve, and we predict that in contiguous reefs strategies will balance dispersal and retention mechanisms, whilst retention mechanisms must predominate on isolated reefs (this effect is explored for the Great Barrier Reef, the Red Sea, and the Maldives in an earlier model in Dytham 2003).

The range of relative mortality rates used in this study affected the emerging levels of self-recruitment considerably. At the lowest mortality level, where survivorship was around $30 \%$ for individuals that remained on the reef, movement did not emerge as a strategy (Fig. 3). Not surprisingly, the effect of this was that self-recruitment was almost $100 \%$. However, increased mortality on the reef drove individuals to move more frequently, and so the level of betweenreef dispersal increased. The movement rate that evolved was asymptotic at high mortality rates, and this trend was repeated for the level of self-recruitment which settled at around $50 \%$. This is far higher than would be predicted from an 'open population' model, and is much more in agreement with recent empirical work that has provided estimates of self-recruitment of $60 \%$ (Almany et al. 2007). Analysis of data for individual landscapes found that the self-recruitment levels were not globally standard, but rather were highly landscape-specific (Fig. 7). Ultimately, at high larval mortality levels, populations evolved similar strategies (Landscapes A to C), or else they became extinct if 
high movement did not guarantee dispersal between reefs (Landscape D).

Our results show that there was clearly a cost of movement, demonstrated by the size of the populations that were sustained after 180 generations as rising larval mortality rates forced greater dispersal strategies (Fig. 4). This suggests a trade-off between either remaining on the reef (and risking survival), or maximising dispersal (and getting lost). Averaging across all the landscapes, only at the 2 lowest larval mortality rates did the mean population size increase from the initial 1000 adults. The effect of the landscape on the population sizes was pronounced, and while some populations were driven to extinction by increased mortality, some landscapes sustained populations that were consistently larger than others. There was also clear evidence of crowding on the reef cells that were populated. At $M_{\mathrm{r}}=0.0005$, the mean population size was 784 adults, which if distributed evenly across the reefs, would be one fish every 1.6 cells (or $63 \%$ occupancy). While the potential fecundity was 10 offspring per adult, the realised fecundity was actually $\sim 4$ per adult at this mortality rate, indicating a density of 2.5 fish per inhabited reef cell, inferring that there was only $25 \%$ reef cell occupancy. Together, these results predict that reef fish populations will be limited by the recruitment of larvae, and that populations may be limited in their potential output due to individuals being 'packed' into areas that are determined by larval supply.

\section{Future directions}

In order to investigate in isolation the effect of onreef larval mortality rates on population-level dispersal strategies, we made several assumptions in applying individual-based modelling (IBM) techniques. First, we used a highly simplified life history, without any post-settlement processes except density-dependent fecundity, and no intergenerational overlap. An obvious challenge for further work would be to include post-settlement processes, such as sexual behaviour, competition for resources, and even interspecific interactions. Second, we assumed direct genetic inheritance of dispersal strategies, with a highly simplified mutation model to facilitate evolution. It would be valuable in the future to improve our model in terms of how components of a dispersal strategy (e.g. movement rate, length of larval life, length of settlement window) may evolve. Third, we stylised our model on an 'average damselfish larva'. There is a high degree of variation among the larval stages of coral reef fishes (among taxa, ontogenies, regions), which should be explored in further modelling studies using parameters taken from real fish.
Fourth, we used highly simplified landscapes. We assumed that each reef cell was of equal quality, and that the reefs were stable environments over 180 generations. It would be interesting to investigate dispersal strategies that evolve in temporally and spatially heterogeneous landscapes, especially to explore the effects of human and environmental disturbances that are degrading natural reef habitats at increasingly alarming rates. It will also be possible, by coupling these models with geographic information systems techniques, to explore 'real world' scenarios, and ask targeted management-based questions about reef fish populations.

In this study, we used a random walk model to simulate the movement of larvae. The impact of this is that we assume that whatever the oceanographic climate, the net displacement will be zero (see Sponaugle et al. [2002] for a review of oceanographic features that may influence dispersal). We also assumed that the movement ability (e.g. swimming ability) of the larvae is constant throughout development. There is evidence from studies on many scales that demonstrates heterogeneous water movement around coral reef environments (e.g. Black \& Moran 1991), as well as studies that report ontogenic changes in swimming abilities through larval life (Leis 2006). A challenge for the future will be to marry IBMs with realistic oceanographic (3-dimensional) models, and then incorporate the potential movements of developing larvae to make useful predictions of population structures over ecological (Cowen et al. 2006) and evolutionary timescales. This is an essential step for using simulation modelling to assist in managing populations for fisheries or conservation objectives.

A second impact of using a random walk model for larval movements is that we have discounted behavioural orientation and homing behaviour of larvae. Recent work has highlighted the use of olfactory (Atema et al. 2002) and acoustic (Simpson et al. 2004, Simpson et al. 2005a, Montgomery et al. 2006) cues by larval reef fishes. It will be a great advance to have field measurements that allow the 'cuescape', or sensory landscape, that larval fishes are exposed to while at sea to be characterised, and to use directed movement models to incorporate the substantial behavioural abilities of larvae in future studies. Previous mathematical modelling approaches have predicted that the size of the sensory zone around reefs may determine the recruitment behaviour of larvae (Armsworth 2000).

\section{CONCLUSIONS}

An increase in the rate of larval mortality on the reef relative to that at sea is sufficient to force a pelagic 
larval phase in coral reef fishes. Although this has negative effects at the population level (indicated by population size), at the individual level it enables the refuge of the ocean to be utilised. It may also have benefits at the individual level by increasing the fecundity of those that are well-adapted to certain conditions. Not surprisingly, increased movement strategies meant that dispersal between reefs increased in our model. However, this effect rarely caused self-recruitment to drop below $50 \%$, and never did we see what would be considered 'open populations'. Due to obvious limitations in what questions can be addressed using field collections and observation studies, we hope that the application of IBMs will continue to improve our understanding of the complex metapopulation structures of coral reef fishes.

Acknowledgements. We thank J. Kemp, M. Priest, D. Nettleton and J. King for many valuable discussions during the development of this work, and 3 anonymous reviewers for their valuable comments. Funding to S.D.S provided by a NERC postdoctoral research fellowship.

\section{LITERATURE CITED}

Almany GR, Webster MS (2006) The predation gauntlet: early post-settlement mortality in reef fishes. Coral Reefs 25: $19-22$

Almany GR, Berumen ML, Thorrold SR, Planes S, Jones GP (2007) Local replenishment of coral reef fish populations in a marine reserve. Science 316:742-744

Armsworth PR (2000) Modelling the swimming response of late stage larval reef fish to different stimuli. Mar Ecol Prog Ser 195:231-247

Atema J, Kingsford MJ, Gerlach G (2002) Larval reef fish could use odour for detection, retention and orientation to reefs. Mar Ecol Prog Ser 241:151-160

Bailey KM, Houde ED (1989) Predation on eggs and larvae of marine fishes and the recruitment problem. Adv Mar Biol 25:1-83

Black KP, Moran PJ (1991) Influence of hydrodynamics on the passive dispersal and initial recruitment of larvae of Acanthaster planci (Echinodermata, Asteroidea) on the Great Barrier Reef. Mar Ecol Prog Ser 69:55-65

Bonhomme F, Planes S (2000) Some evolutionary arguments about what maintains the pelagic interval in reef fishes. Environ Biol Fishes 59:365-383

Booth D, Alquezar R (2002) Food supplementation increases larval growth, condition and survival of Acanthochromis polyacanthus. J Fish Biol 60:1126-1133

Brown JH, Kodric-Brown A (1977) Turnover rates in insular biogeography: effect of immigration on extinction. Ecology 58:445-449

Codling EA, Hill NA, Pitchford JW, Simpson SD (2004) Random walk models for the movement and recruitment of reef fish larvae. Mar Ecol Prog Ser 279:215-224

Cowen RK, Paris BB, Srinivasan A (2006) Scaling of connectivity in marine populations. Science 311:522-527

Doherty PJ, Williams DM, Sale PF (1985) The adaptive significance of larval dispersal in coral reef fishes. Environ Biol Fishes 12:81-90
Dufour V, Riclet E, LoYat A (1996) Colonization of reef fishes at Moorea Island, French Polynesia: temporal and spatial variation of the larval flux. Mar Freshw Res 47:413-422

Dytham C (2003) How landscapes affect the evolution of dispersal behaviour in reef fishes: results from an individualbased model. J Fish Biol 63:213-225

Godfray HCJ (1995) Evolutionary theory of parent-offspring conflict. Nature 376:133-138

Hamner WM, Jones MS, Carleton JH, Hauri IR, Williams DM (1988) Zooplankton, planktivorous fish, and water currents on a windward reef face: Great Barrier Reef, Australia. Bull Mar Sci 42:459-479

Hensley DA, Appeldoorn RS, Shapiro DY, Ray M, Turingan RG (1994) Egg dispersal in a Caribbean coral reef fish, Thalassoma bifasciatum. 1. Dispersal over the reef platform. Bull Mar Sci 54:256-270

Houde ED (1989) Comparative growth, mortality, and energetics of marine fish larvae: temperature and implied latitudinal effects. Fish Bull 87:471-495

James MK, Armsworth PR, Mason LB, Bode L (2002) The structure of reef fish metapopulations: modelling larval dispersal and retention patterns. Proc R Soc Lond Ser B 269:2079-2086

Johannes RE (1978) Reproductive strategies of coastal marine fishes in the tropics. Environ Biol Fish 3:65-84

Leis JM (1991) The pelagic stage of reef fishes: the larval biology of coral reef fishes. In: Sale PF (ed) The ecology of fishes on coral reefs. Academic Press, San Diego, p 183-230

Leis JM (2006) Are larvae of demersal fishes plankton or nekton? Adv Mar Biol 51:57-141

Leis JM, McCormick MI (2002) The biology, behaviour, and ecology of the pelagic, larval stage of coral reef fishes. In: Sale PF (ed) Coral reef fishes: dynamics and diversity in a complex ecosystem. Academic Press, San Diego, p 171-199

Leis JM, Sweatman HPA, Reader SE (1996) What the pelagic stages of coral reef fishes are doing out in blue water: daytime field observations of larval behavioural capabilities. Mar Freshw Res 47:401-411

Margulies D (1993) Assessment of the nutritional condition of larval and early juvenile tuna and spanish mackerel (Pisces, Scombridae) in the Panama Bight. Mar Biol 115: $317-330$

McAlary FA, McFarland WN (1993) The effect of light and darkness on hatching in the pomacentrid Abudefduf saxatilis. Environ Biol Fish 37:237-244

Montgomery JC, Jeffs A, Simpson SD, Meekan MG, Tindle C (2006) Sound as an orientation clue for the pelagic larvae of reef fish and crustaceans. Adv Mar Biol 51:143-196

Motro U (1991) Avoiding inbreeding and sibling competition: the evolution of sexual dimorphism for dispersal. Am Nat 137:108-115

Planes S, Fauvelot C (2002) Isolation by distance and vicariance drive genetic structure of a coral reef fish in the Pacific Ocean. Evolution 56:378-399

Sale PF (1991) Reef fish communities: open nonequilibrial systems. In: Sale PF (ed) The ecology of fishes on coral reefs. Academic Press, San Diego, p 564-598

Simpson SD, Meekan MG, McCauley RD, Jeffs A (2004) Attraction of settlement-stage coral reef fishes to reef noise. Mar Ecol Prog Ser 276:263-268

Simpson SD, Meekan M, Montgomery J, McCauley R, Jeffs A (2005a) Homeward sound. Science 308:221

Simpson SD, Yan HY, Wittenrich ML, Meekan MG (2005b) Response of embryonic coral reef fishes (Pomacentridae: Amphiprion spp.) to noise. Mar Ecol Prog Ser 287:201-208 
Sponaugle S, Cowen RK, Shanks A, Morgan SG and 7 others (2002) Predicting self-recruitment in marine populations: biophysical correlates and mechanisms. Bull Mar Sci 70: 341-375

Swearer SE, Caselle JE, Lea DW, Warner RR (1999) Larval retention and recruitment in an island population of a coral-reef fish. Nature 402:799-802

Swearer SE, Shima JS, Hellberg ME, Thorrold SR and 6 others (2002) Evidence of self-recruitment in demersal marine populations. Bull Mar Sci 70:251-271

Editorial responsibility: Otto Kinne (Editor-in-Chief), Oldendorf/Luhe, Germany
Travis JMJ, Dytham C (1998) The evolution of dispersal in a metapopulation: a spatially explicit, individual-based model. Proc R Soc Lond Ser B 265:17-23

Travis JMJ, Murrell DJ, Dytham C (1999) The evolution of density-dependent dispersal. Proc R Soc Lond Ser B 266: $1837-1842$

Warner RR, Swearer SE, Caselle JE (2000) Larval accumulation and retention: implications for the design of marine reserves and essential fish habitat. Bull Mar Sci 66: $821-830$

Submitted: March 7, 2006; Accepted: May 9, 2007

Proofs received from author(s): September 10, 2007 